\title{
Long-Term Follow-Up Results following Elective Treatment of Unruptured Intracranial Aneurysms with the Pipeline Embolization Device
}

A.H.Y. Chiu, A.K. Cheung, J.D. Wenderoth, L. De Villiers, H. Rice, C.C. Phatouros, T.P. Singh, T.J. Phillips, and W. McAuliffe

\begin{abstract}
BACKGROUND AND PURPOSE: Numerous reports of treatment of wide-neck aneurysms by flow diverters have been published; however, long-term outcomes remain uncertain. This article reports the imaging results of unruptured aneurysms treated electively with the Pipeline Embolization Device for up to 56 months and clinical results for up to 61 months.
\end{abstract}

MATERIALS AND METHODS: One hundred nineteen aneurysms in 98 patients from 3 centers admitted between August 2009 and June 2011 were followed at 6-month, 1-year, and 2+-year postprocedural timeframes. Analyses on the effects of incorporated vessels, previous stent placement, aneurysm size, and morphology on aneurysm occlusion were performed.

RESULTS: The 1- and 2+-year imaging follow-ups were performed, on average, 13 and 28 months postprocedure. At 2+-year follow-up, clinical data were $100 \%$ complete and imaging data were complete for 103/116 aneurysms (88.8\%) with a $93.2 \%$ occlusion rate. From 0 to 6 months, TIA, minor stroke, and major stroke rates were $4.2 \%, 3.4 \%$, and $0.8 \%$ respectively. After 6 months, 1 patient had a TIA of uncertain cause, with an overall Pipeline Embolization Device-related mortality rate of $0.8 \%$. An incorporated vessel was significant for a delay in occlusion $(P=.009)$ and nonocclusion at 6 months and 1 year, with a delayed mean time of occlusion from 9.1 months $(95 \% \mathrm{Cl}, 7.1-11.1$ months) to 16.7 months ( $95 \% \mathrm{Cl}, 11.4-22.0$ months). Other factors were nonsignificant.

CONCLUSIONS: The Pipeline Embolization Device demonstrates continued very high closure rates at $2+$ years, with few delayed clinical adverse sequelae. The presence of an incorporated vessel in the wall of the aneurysm causes a delay in occlusion that approaches sidewall closure rates by 2 years.

ABBREVIATIONS: DAT $=$ dual antiplatelet therapy; $\mathrm{PED}=$ Pipeline Embolization Device

T he endovascular treatment of wide-neck aneurysms by flowdiverting devices has been previously been evaluated for both small and large aneurysms. The midterm results of implantation of the Pipeline Embolization Device (PED; Covidien, Irvine, California) have been previously reported. ${ }^{1-6}$ Data collection is now complete for up to 56 months with a mean of 28 months, and we report the results in patients who have previously undergone elective treatment with the PED.

\section{MATERIALS AND METHODS \\ Patient Population}

A previously published existing prospective case registry ${ }^{4}$ of PEDtreated elective cases (wide neck, $>4 \mathrm{~mm}$; unfavorable dome/neck

Received October 15, 2014; accepted after revision February 2, 2015.

From the Neurological Intervention and Imaging Service (Western Australia) (A.H.Y.C., A.K.C., C.C.P., T.P.S., T.J.P., W.M.), Perth, Australia; Prince of Wales and Liverpool Hospitals (A.K.C., J.D.W.), Sydney, Australia; and Gold Coast University Hospital (L.D.V., H.R.), Gold Coast, Australia.

Please address correspondence to Albert H.Y. Chiu, MBBS (Hons.), FRANZCR, Neurological Intervention and Imaging Service (WA), Sir Charles Gairdner Hospital, 1st Floor, G Block, Hospital Ave, Nedlands, WA 6009, Australia; e-mail: albert.h.chiu@gmail.com http://dx.doi.org/10.3174/ajnr.A4329 ratio, $<1.6$; fusiform anatomy, $>10 \mathrm{~mm}$; or previous failed therapy) at 3 centers between August 2009 and June 2011 identified 119 unruptured aneurysms in 98 patients undergoing 107 consecutive elective procedures. This includes the 57 consecutive cases originally reported. Only elective procedures were included to increase population homogeneity. Written informed consent was obtained. Periprocedural management, multidisciplinary involvement, and application for use are as previously published. ${ }^{4}$ Morbidity or death occurring for any reason during follow-up was noted.

\section{Antiplatelet and Anticoagulation Schedule}

Antiplatelet and anticoagulation schedules have been published previously. ${ }^{4}$ Antiplatelet protocols, use of platelet-inhibition testing, and duration of dual antiplatelet therapy (DAT) for anterior circulation aneurysms (3-6 months) varied among operators; however, all patients with posterior circulation aneurysms were prescribed 12 months of DAT routinely. Patients continued/discontinued DAT outside these timeframes at operator discretion. All continued to receive aspirin after cessation of clopidogrel, except for 3 patients: Two were continued on clopidogrel, one for an 
Table 1: Characteristics of the 7 aneurysms that failed to close during the study

\begin{tabular}{|c|c|c|c|c|c|}
\hline Location & $\begin{array}{l}\text { Aneurysm } \\
\text { Size }(\mathrm{mm})\end{array}$ & $\begin{array}{c}\text { Neck } \\
\text { Diameter }(\mathrm{mm})\end{array}$ & $\begin{array}{c}\text { Incorporated } \\
\text { Branch }\end{array}$ & $\begin{array}{c}\text { Final Imaged } \\
\text { Aneurysm Size }(\mathrm{mm})\end{array}$ & Comments \\
\hline PcomA & 8 & 5 & $\mathrm{Y}$ & 5 & Patient B, previous PED (initially $15-\mathrm{mm}$ \\
\hline Cavernous & 18 & Fusiform & $\mathrm{N}$ & 9 & aneurysm/7-mm neck) \\
\hline Basilar & 15 & 6 & $\mathrm{~N}$ & 10 & Patient A \\
\hline AcomA & 13 & 10 & $\mathrm{~N}$ & 4 & \\
\hline Paraclinoid & 10 & 10 & $\mathrm{~N}$ & 1 & Previous stent coiling \\
\hline MCA & 3 & 2 & $\mathrm{Y}$ & Unchanged & \\
\hline PcomA & 5 & 4 & $\mathrm{Y}$ & Unchanged & \\
\hline
\end{tabular}

Note:-Y indicates yes; N, No; PcomA, posterior communicating artery; AcomA, anterior communicating artery.

unrelated cardiac procedure and the other for aspirin intolerance; one remained on dipyramidole for aspirin allergy.

\section{Follow-Up Study Intervals and End Points}

Clinical follow-up was recorded. Imaging follow-up was noted at approximately 6-month, 1-year, and 2+-year timeframes and was grouped as per intention-to-perform at the particular interval, but exact times varied depending on patient availability. The primary end point was defined as complete aneurysm closure, and secondary end points included in-stent stenosis, retreatment, and delayed complications, including TIA, minor stroke (mRS, 0-2), major stroke (mRS, 3-6), and SAH. Imaging was performed as a DSA or, less commonly, as MR angiography or CTA if patients were infirm or refused DSA. If delayed imaging follow-up was not performed (due to patient infirmity, refusal, or other), clinical follow-up was undertaken by outpatient clinic or telephone. Follow-up was performed earlier at the operator's discretion if there were concerns.

\section{Statistical Analysis}

The presence of a notable artery arising from the aneurysm (ie, incorporated [yes/no], pre-existing stent [yes/no], size [dichotomized into $<10 / \geq 10 \mathrm{~mm}$ ], and aneurysm morphology [berry/ fusiform]) was analyzed with respect to occlusion rates at the 6-month, 1-year, and 2+-year timeframes by using the Fisher test (GraphPad Prism software; GraphPad Software, San Diego, California). Multiple regression was performed by using SPSS, Version 22 (IBM, Armonk, New York), and statistically significant associations were assessed for delay in occlusion by using KaplanMeier analysis.

For calculating aneurysm occlusion percentages, we made 2 assumptions: Aneurysms of patients missing a follow-up period but with documented occlusion before and after were assumed to have remained occluded. Second, if an aneurysm was nonoccluded at the last imaging examination, it was assumed to have remained nonoccluded regardless of additional clinical followup. We reviewed prior imaging in aneurysms occluded before the 6-month follow-up period for the Kaplan-Meier analysis to establish the date of occlusion.

\section{RESULTS}

We included 119 aneurysms in 98 patients (78 female; 13-83 years of age; mean, 55.7 years) treated in 107 consecutive procedures: $43.7 \%(52 / 119)$ of aneurysms were $\geq 10 \mathrm{~mm}$; of these, 7 were giant ( $>25 \mathrm{~mm}) ; 17.6 \%(21 / 119)$ were posterior circulation; $16.0 \%$ (19/119) were fusiform; $19.3 \%$ (23/119) had a notable in- corporated branch; and $8.4 \%$ (10/119) had previous stent therapy.

Of the 119 aneurysms, $100 \%(116 / 116)$ had clinical follow-up and $88.8 \%(103 / 116)$ had imaging follow-up to $2+$-years. Aneurysms in 11 patients $(9.5 \%)$ were previously occluded and did not have imaging at the $2+$-year timeframe. Two patients with 2 aneurysms refused imaging follow-up entirely and were excluded from occlusion analysis. Three deaths occurred, all between the 1and 2+-year follow-up. Eighty-four percent (100/119) were imaged at 6 months, and 65.6\% (78/119), at 1-year. Six-month follow-up ranged from 1 to 10 months (average and median, 6 months); 1-year follow-up, from 8 to 19 months (average and median, $13 \pm 2.1$ months); and 2+-year follow-up, from 17 to 56 months (average, 28 months; median, $26 \pm 7.8$ months). Average and median clinical 2+-year follow-up was 31 and 30 months, respectively (range, 17-61 months).

\section{Aneurysmal Occlusion}

Overall aneurysmal occlusion rates increased from $81.6 \%, 84.1 \%$, to $93.2 \%$ in the 6 -month, 1 -year, and $2+$-year time periods, respectively. Twenty-one of 119 aneurysms were identified as nonoccluded at 6 months; of these, 3 closed by 1-year follow-up, and a further 11, at 2+-year follow-up.

Seven aneurysms were nonoccluded at 2+-year follow-up (Table 1). Four of these patients had stopped clopidogrel at 6 months. Three of 7 patients had an incorporated vessel (discussed below). Two of these 3 patients stopped clopidogrel at 6 months. Of the 4/7 remaining aneurysms, the first (cavernous aneurysm) was initially treated with $1 \mathrm{PED}(5 \times 20 \mathrm{~mm})$ and had retreatment with a second $(4.75 \times 16 \mathrm{~mm})$ at 12 months. Final CTA was performed 22 months post-initial PED, after which follow-up was stopped due to the patient being 80 years of age. The second case, patient A (Fig 1), had a basilar blowout aneurysm that was retreated at 20 months (discussed below). The third had a blowout aneurysm of the anterior communicating artery treated with a PED from the left A1 to the right A1/A2 junction without convincing purchase in the distal right A2. The last had a pre-existing stent (Enterprise; Codman \& Shurtleff, Raynham, Massachusetts).

\section{Presence of Incorporated Vessel}

Of the 21 nonoccluded aneurysms at 6 months, 10 had an incorporated vessel. This was statistically significant for causing delayed occlusion $(P=.009)$ and nonocclusion at 6 months $(10 / 23$ aneurysms with an incorporated vessel, $P<.001)$, and at 1 year $(10 / 23, P<.001)$, but not at $2+$ years $(3 / 23, P=.116)$. Kaplan- 


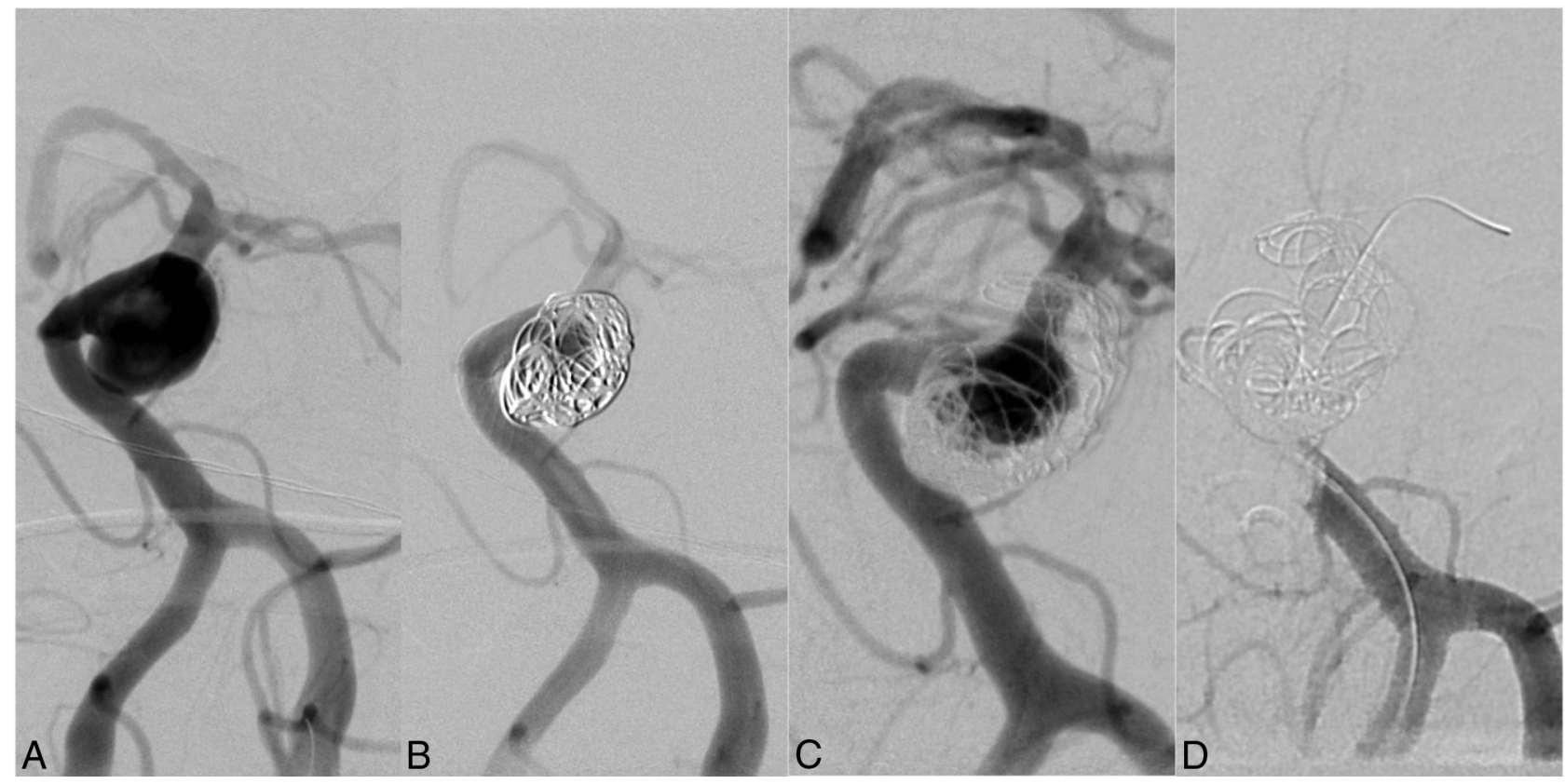

FIG 1. Frontal-projection DSA images of the basilar artery. Patient $A$ is a 69-year-old man who lived in a remote location and presented with syncope and vertigo caused by mass effect from a $15-\mathrm{mm}$ sidewall blowout basilar trunk aneurysm. $A$, Pretreatment DSA. $B$, This was initially treated with 2 PEDs $(4 \times 14 \mathrm{~mm}, 4 \times 18 \mathrm{~mm})$ and coils (at operator discretion) but continued to fill at 18 months, despite cessation of symptoms and clopidogrel being stopped prematurely at 6 months without issue. A third PED $(4 \times 20 \mathrm{~mm})$ was inserted at 20 months $(C)$, but the aneurysm continued to fill at 27 months on DSA (not shown). At 33 months (13 months after the last PED insertion), clopidogrel was stopped for an inguinal hernia repair in a distant peripheral hospital, resulting in PED construct thrombosis (perioperative heparin was advised), with symptoms arising 1 day after surgery, progressing to left-sided weakness, obtundation, and MR imaging evidence of multiple posterior circulation infarcts. The patient was intubated and flown to our institution, but emergency neurothrombectomy was unsuccessful $(D)$ and the patient died.

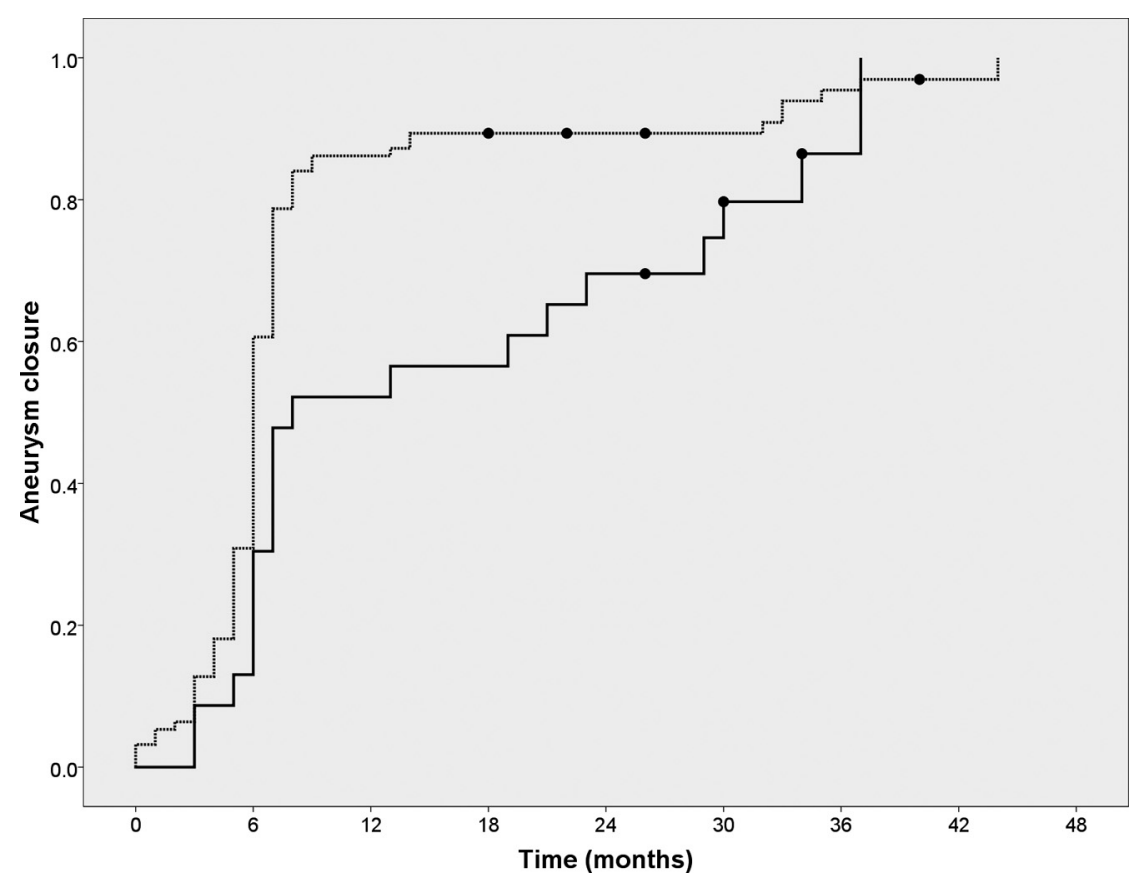

FIG 2. Kaplan-Meier curves of aneurysms with an incorporated vessel (solid line) versus no incorporated vessel (dotted line), demonstrating the delayed occlusion of the former group. Shaded circles represent censored observations (representative of nonoccluded aneurysms at the last known time of imaging).

Meier analysis suggested that the presence of an incorporated vessel results in a mean time of closure at 16.7 months $(95 \% \mathrm{CI}$, 11.4-22.0 months) versus 9.1 months (95\% CI, 7.1-11.1 months) in its absence (Fig 2). Seven of the 10 aneurysms had occluded at final follow-up. Two of 10 remained unchanged in size compared with pretreatment; both had only 1 PED and had 26and 30-month imaging, respectively. The third, patient B (Fig 3), had a second PED at 22 months with $40 \%$ reduction in size at 56-month follow-up.

Ten aneurysms had a previous stent, and of these, 6 demonstrated occlusion at 6 months. At 1-year follow-up, none of the remaining 4 had closed. A further 3 were occluded by $2+$-years $(9 / 10)$. The results trended toward significance for nonocclusion at 1 year but not at other intervals $(P=.131)$. No statistically significant influence on occlusion was found for size or morphology (Table 2).

\section{In-Stent Stenosis or Vessel Occlusion}

Three cases $(2.8 \%)$ of in-stent stenosis $\geq 70 \%$ were noted at 6 months. None of the patients were current smokers; all were female. The narrowing lessened with time, and the patients remained asymptomatic. In these cases, aspirin and clopidogrel were maintained. No new stenoses were identified after 6 months.

Two periprocedural PED occlusions were noted. The first patient (a 66-year-old male smoker) was treated for a 78-mm para- 


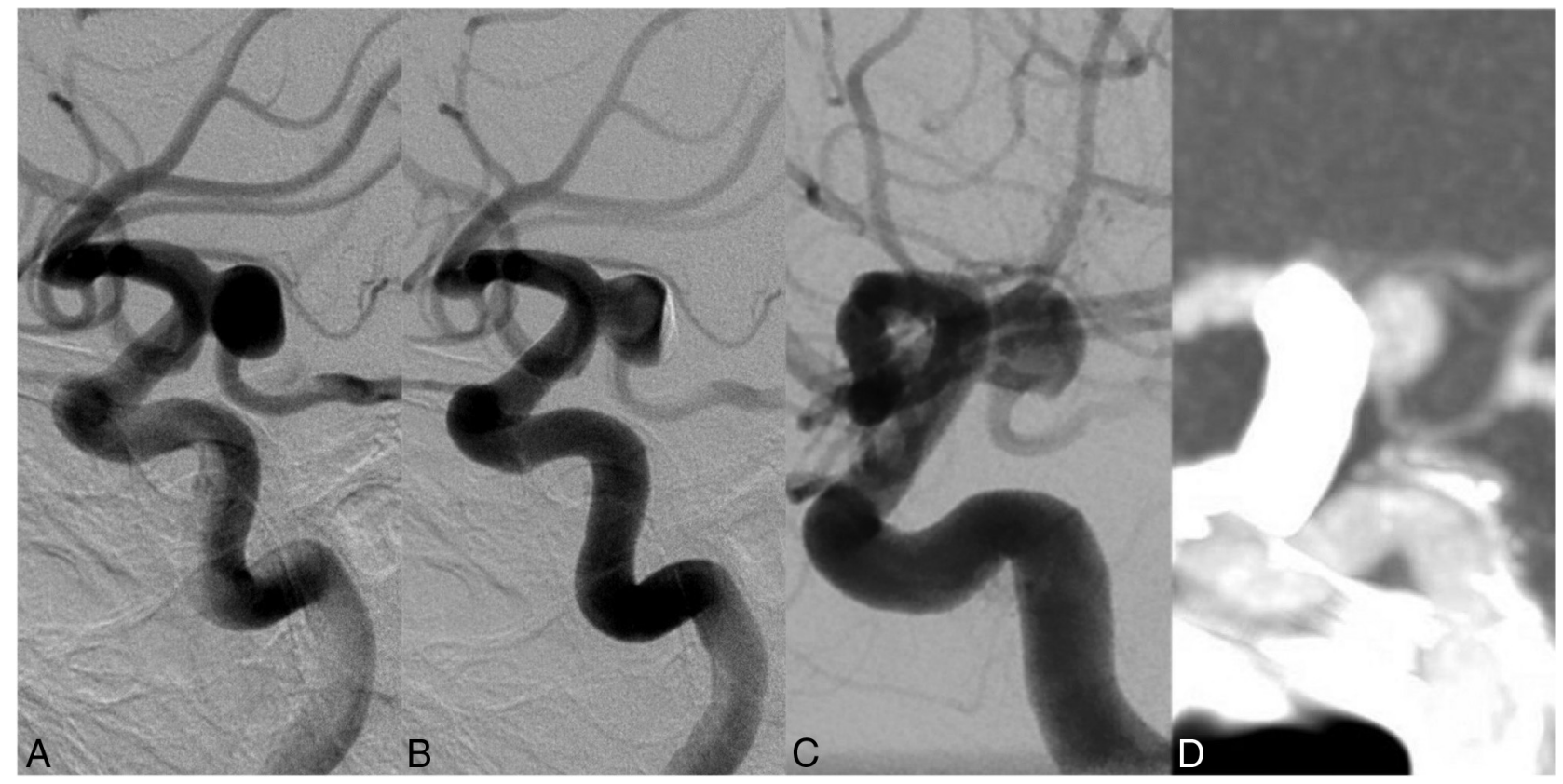

FIG 3. $A-C$, Lateral DSA images of the left ICA. $D$, Sagittal maximum-intensity-projection reconstruction of $C T$ angiography. Patient $B$ is a 63-year-old man who had an asymptomatic left posterior communicating artery aneurysm, initially treated with a single PED ( $3.75 \times 12 \mathrm{~mm})$. Preinsertion $(A)$ and immediate postinsertion images $(B)$ of a flow diverter demonstrate the large incorporated posterior communicating artery. Twenty-two months after insertion of the initial PED, a second $(3.75 \times 14 \mathrm{~mm})$ was inserted (not shown). $C$, Final available catheter angiographic imaging 9 months postinsertion of the second flow diverter. Clopidogrel was stopped 6 months postinsertion of the second PED. D, CT angiography 56 months post-initial flow diversion demonstrates persistence of the aneurysm but with a decrease in its size.

Table 2: Summary of completeness of aneurysm follow-up and occlusion rates since initial flow-diverter therapy

\begin{tabular}{|c|c|c|c|c|c|c|}
\hline \multirow[b]{2}{*}{ Follow-Up Period } & \multirow[b]{2}{*}{6 Months } & \multirow[b]{2}{*}{1 Year } & \multirow[b]{2}{*}{$2+$ Years } & \multicolumn{3}{|c|}{$P$ Value } \\
\hline & & & & 6 Months & 1 Year & $2+$ Years \\
\hline $\begin{array}{l}\text { No. of aneurysms with data available } \\
\text { for analysis }\end{array}$ & $114 / 119$ & $107 / 119$ & $103 / 116$ & & & \\
\hline $\begin{array}{l}\text { Percentage complete } \\
\text { follow-up data }\end{array}$ & 95.8 & 89.9 & 88.8 & & & \\
\hline \multicolumn{7}{|l|}{ Percentage aneurysms occluded } \\
\hline Incorporated vessel & 54.5 & 56.5 & 85.7 & $<.001$ & $<.001$ & .116 \\
\hline No incorporated vessel & 88.0 & 92.3 & 95.7 & & & \\
\hline Pre-existing stent & 66.7 & 66.7 & 90 & .363 & .131 & .484 \\
\hline No pre-existing stent & 82.9 & 86.7 & 94.2 & & & \\
\hline$<10 \mathrm{~mm}$ & 82.5 & 87.3 & 95.3 & .811 & .598 & .697 \\
\hline$\geq 10 \mathrm{~mm}$ & 80.4 & 82.4 & 92 & & & \\
\hline Berry & 82.3 & 85.6 & 93.8 & .741 & .717 & 1 \\
\hline Fusiform & 77.8 & 82.4 & 94.4 & & & \\
\hline Total & 81.6 & 84.1 & 93.2 & & & \\
\hline
\end{tabular}

clinoid aneurysm with 4 PEDs and had complications from acute stent platelet aggregation requiring abciximab. He presented 12 days postprocedure with seizures and in-stent thrombosis. Two passes with a Solitaire $4 \times 15 \mathrm{~mm}$ device (Covidien), an 8-mg bolus of intra-arterial abciximab, and a 12 -hour intravenous infusion resulted in recanalization. The patient was converted to prasugrel. This center had no P2Y12 testing. No clinical sequelae were noted, and CT at day 9 demonstrated no infarcts. The second case occurred during treatment of a pericallosal aneurysm in a 74-year-old patient, resulting in clinically silent stroke (discussed below).

Two delayed PED occlusions were detected. One, in patient $C$, was an asymptomatic occlusion in a 3-layer PED construct in a pericallosal fusiform aneurysm (Fig 4). The second, patient A, was in a 69-year-old man (Fig 1) who died after an elective inguinal hernia repair from thrombosis of his 3-layer PED construct in a blowout basilar aneurysm (discussed below).

\section{Retreatment}

Retreatment by using the PED was required in 3/119 aneurysms in the follow-up period. The first patient, previously published, ${ }^{4}$ initially had an elective flow diversion of a 16-mm superior hypophyseal aneurysm with a single PED. Thirty-four days later, on routine CTA, the PED had migrated proximally. Two PEDs were placed that day. The second, patient A (Fig 1), had a blowout basilar trunk aneurysm. This was treated with 2 telescoped PEDs and coils but continued to fill at 18 months, despite cessation of clopidogrel prematurely at 6 months. Retreatment was performed at 20 months with another PED, but the aneurysm was seen as 


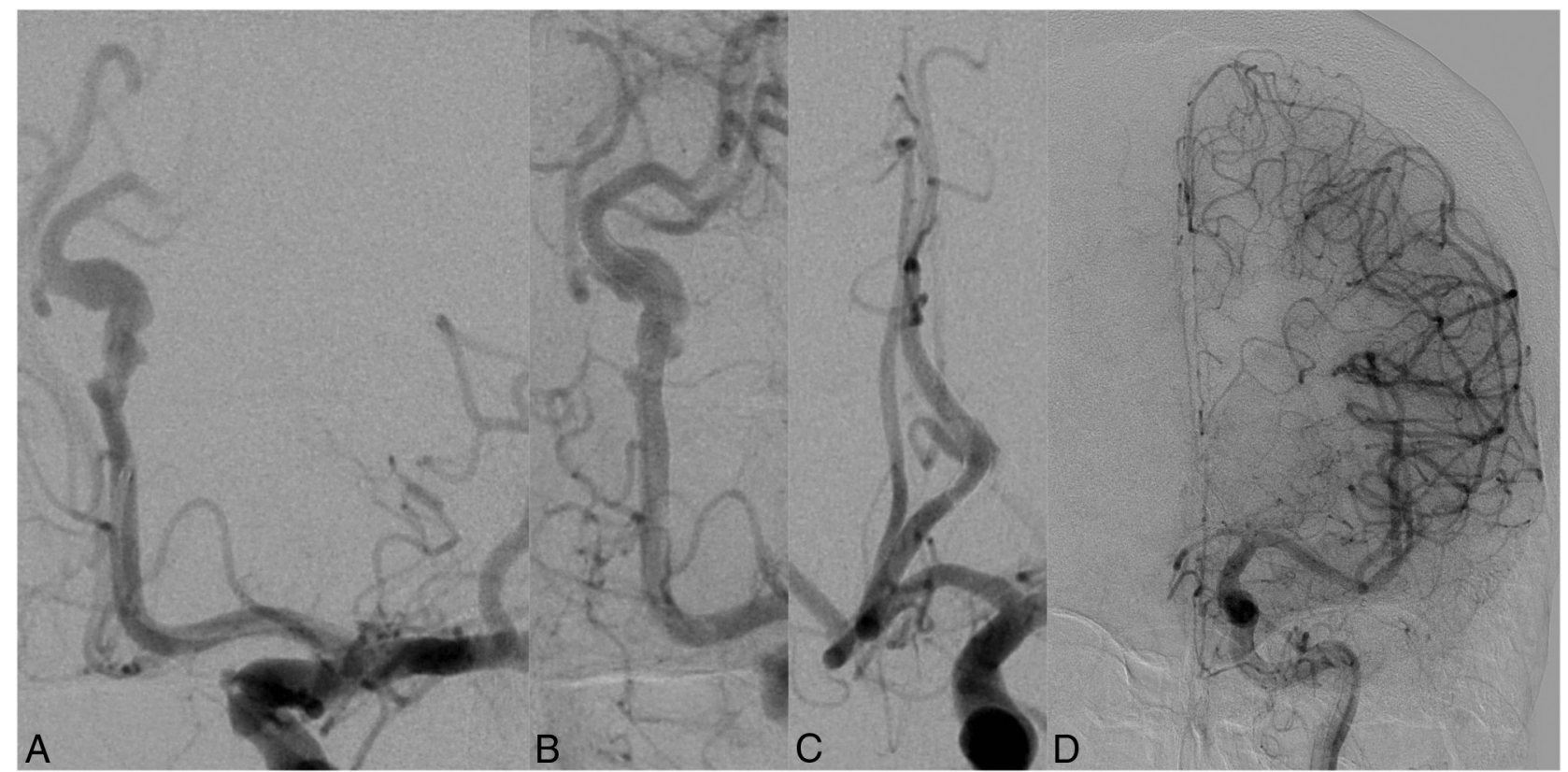

FIG 4. Subtracted frontal views of the left ICA DSA. Patient $C$ is a 62 -year-old nonsmoking woman who had a dysplastic $6 \times 20 \mathrm{~mm}$ pericallosal fusiform aneurysm identified on investigation for headaches and retro-orbital pain. Pretreatment appearance $(A)$ of a dysplastic fusiform A2 segment aneurysm and appearance immediately postdeployment $(B)$ of 3 PEDs $(2.5 \times 20 \mathrm{~mm}, 2.5 \times 18 \mathrm{~mm}$, and $2.5 \times 14 \mathrm{~mm})$. Clopidogrel was stopped after 6 months, and aspirin was continued. C, At DSA 21 months post-PED deployment, the aneurysm demonstrates $90 \%$ occlusion with no in-stent stenosis, but spontaneous asymptomatic PED occlusion is found at 35 months $(D)$. It is unknown exactly when the PED construct thrombosed (between 21 and 35 months postimplantation) because the patient was asymptomatic.

continuing to fill at 27 -month DSA. ${ }^{7}$ The third case was a 77 -yearold patient presenting with abducens palsy from an $18-\mathrm{mm}$ cavernous aneurysm. Due to nonocclusion at 11 months, a second PED was placed, but the aneurysm remained open, albeit smaller ( $9 \mathrm{~mm})$, at 22 months. The sixth nerve palsy resolved. This case was classed as a nonocclusion because the patient declined further imaging.

\section{Transient Ischemic Attacks, Strokes, Subarachnoid Hemorrhage, and Deaths}

From 0 to 6 months, in addition to the 5 TIAs and 3 strokes (all mRS 1 ) in the previously reported population, ${ }^{4,7} 2$ strokes occurred, for a rate of TIA of $4.2 \%$, minor stroke of $3.4 \%$, and major stroke of $0.8 \%$. The first was in a 57 -year-old smoker who underwent elective flow diversion for a recurrent 5-mm right MCA aneurysm, previously coiled for acute rupture in 2009. A single $3 \times 14 \mathrm{~mm}$ PED was placed uneventfully. The patient's clopidogrel was stopped against instructions for hematuria 11 days postprocedure, and he had an infarct on day 17, with hemiplegia and severe dysphasia (mRS 3 ). The second was a clinically silent stroke occurring in a 74-year-old patient with a 4-mm pericallosal aneurysm. Two PEDs were placed, and intraprocedural PED occlusion occurred; thus, $4 \mathrm{mg}$ of intra-arterial abciximab was administered. Recanalization occurred within 15 minutes, and the patient remained asymptomatic. Despite this outcome, frontopolar branch and medial lenticulostriate infarcts were noted on routine 1-month CT. The patient remained neurologically intact (mRS 0). Of note, the center also did not use P2Y12 testing.

From 6-month follow-up onward, 1 case of TIA was noted, a 62-year-old smoker who experienced 3 possible TIAs on aspirin between 26 and 53 months post-PED with normal clinical examination and MR imaging findings. No action was taken.
Three deaths occurred during follow-up from all causes, for a mortality rate of $2.5 \%$, with a PED-related mortality of $0.8 \%$. In the first, patient A (Fig 1), the PED thrombosed, and he died at 33 months after initial insertion of 2 PEDs for his blowout basilar aneurysm (13 months after retreatment with a third PED) after stopping clopidogrel for an elective inguinal hernia repair. The second was a 58-year-old man with active non-Hodgkin lymphoma who died of unrelated causes 17 months after receiving a PED. The third was a 66-year-old patient who had undergone treatment of a 78-mm aneurysm with 4 PEDs and was placed on aspirin and prasugrel (clopidogrel resistance). The aneurysm was thrombosed at 6-month DSA, but DAT was continued for heavy smoking, and he died 12 months later from a fall-related posttraumatic right frontal hematoma.

\section{DISCUSSION}

Flow diversion has been demonstrated effective in treating aneurysms, ${ }^{1-6}$ enabling repair without the need to enter the sac. These stentlike devices reduce aneurysm perfusion by directing flow through the lumen of the stent bypassing the neck, inducing aneurysm thrombosis while maintaining perfusion to side branches. Most recent articles have focused on the uncommon short- to medium-term complications of ipsilateral parenchymal hemorrhage, ${ }^{8-12}$ delayed rupture ${ }^{1,13,14}$ and side branch occlusion, ${ }^{7,15}$ or thromboembolism ${ }^{2,6,12,16}$; there is an evolving understanding of flow-diversion complications. However, the body of knowledge relating to the long-term effects of flow diversion is still incomplete.

In our cohort, delayed aneurysmal nonocclusion is statistically associated with the presence of an incorporated vessel. The presence of flow demand is the premise by which small perforators 
jailed by the PED are preserved; however, it is likely that this plays an important role in prolonging aneurysmal perfusion in these cases. Such aneurysms have been described as remodeling into an infundibulum-like structure, ${ }^{5}$ and this study suggests that such a process may take longer but will eventually occur. This finding is similar to a recent study of MCA aneurysms ${ }^{17}$ in which the 6-month occlusion rate was $85.7 \%$ versus $91.2 \%$ in the larger study addressing all aneurysms. ${ }^{5}$ This finding is important, given that flow diverters are sometimes a preferred option in such cases; an analysis by Brinjikji et al ${ }^{18}$ suggested that $22 \%$ of aneurysms may fall into this category. Most aneurysms appear to close following cessation of clopidogrel; thus, this is an important strategy to consider to promote aneurysm closure. Not all aneurysms, however, may respond because 2 of 3 patients with an incorporated vessel and nonocclusion at 2+-years had stopped clopidogrel at 6 months.

One explanation is that an incorporated branch decreases the slow, turbulent flow achieved in flow diversion of a stand-alone aneurysm; thus, the efficacy of clot formation is reduced. Only 1 of these patients had an additional PED placed to promote aneurysm closure, and perhaps additional PEDs in a delayed fashion need to be considered. This staging of treatment maximizes the temporal development of pial-pial collateralization, with the vascular territory of the incorporated branch being devolved to neighboring vessels. This result is clearly seen in flow diversion ${ }^{15}$; with a diminished requirement for high flow at the incorporated vessel, eventual aneurysm thrombosis should occur.

Our rate of severe in-stent stenosis is similar to that previously published $^{1,4,5,19}$; all remained asymptomatic and the stenoses reduced with time. It would seem reasonable to continue DAT until there is an observable reduction of narrowing to at least $50 \%$.

Two cases of delayed PED occlusion were encountered at 33 and 35 months. The first, patient A (Fig 1), occurred in a large blowout aneurysm with cessation of clopidogrel for elective surgery. Delayed thrombosis of the basilar artery in these aneurysms has been previously reported, and life-long DAT may well be required in these cases. ${ }^{20}$ Intimal cover in large/giant basilar aneurysms may never occur or may be slow. The second case involved asymptomatic occlusion of an A2 vessel with 3 overlapping PEDs in a fusiform aneurysm, representing a big metal load in a small vessel. Slow asymptomatic occlusion of vessels is recognized, and the phenomenon has been reported by previous authors ${ }^{19,21}$; there may be a relation to the cessation of clopidogrel, and lifetime DAT may be required in multiple overlapping PEDs in smaller vessels.

Delayed aneurysm rupture did not occur in our cohort. This phenomenon has previously been described in large or giant aneurysms. ${ }^{13}$ Fifty-six percent of our cohort consisted of aneurysms of $<10 \mathrm{~mm}$. This supports a theory that delayed PED-related rupture is rare in smaller aneurysms.

Our occlusion rates for comparable periods are similar to those published. ${ }^{4-6,22-24}$ They add to the information gleaned by O'Kelly et al, ${ }^{19}$ who studied a cohort of 97 PEDs to a median follow-up 1.25 years, but from a range of $0.25-2.5$ years. Saatci et $\mathrm{al}^{5}$ were able to follow up a minority of cases at $18-24$ months (69 aneurysms [27.5\%] in 49/191 patients; 25.7\%). Similarly, Szikora et $\mathrm{al}^{2}$ followed a small cohort (12/19 aneurysms, 63.1\%) between 1.5 and 2 years with MRA. A third series starting with a cohort of 178 aneurysms in 143 patients and followed 58 aneurysms to 18 months. ${ }^{25}$ Other larger case series followed patients to approximately an average of $\leq 1$ year. ${ }^{1,3,6,19}$ A small study of 12 patients demonstrated that all except 1 aneurysm occluded at 6-month angiography, but the authors continued to follow the cohort by CT or MR angiography to a range of $12-47$ months. ${ }^{26}$ Our cohort represents the largest and longest reported imaging follow-up (average duration of 28 months and a maximum follow-up of 56 months postprocedure) and clinical follow-up (average of 31 months and median of 30 months). Moreover, at $2+$ years high clinical $(100 \%)$ and imaging $(88.8 \%)$ follow-up rates were achieved, both markedly higher compared with other published data during this time. These data give surety to the efficacy of the response to PEDs because there was no loss of patients at follow-up.

A number of limitations to our study are noted. The imaging follow-up at $2+$ years is very high but, nevertheless, incomplete. Long-term $100 \%$ imaging follow-up is difficult despite a diligent approach because patients are geographically mobile and can decline follow-up. The basis of the study was taken from a registry, and the retrospective nature limited the flexibility of statistical analysis.

\section{CONCLUSIONS}

The PED demonstrates continued favorable clinical and imaging findings up to 61 and 56 months postprocedure, respectively. From 0 to 6 months, the TIA, minor stroke, and major stroke rates were $4.2 \%, 3.4 \%$, and $0.8 \%$, respectively. The TIA rate from 6 months onward was $0.8 \%$, with a PED-related mortality rate of $0.8 \%$. The treatment is durable, complete, and reliable. The presence of an incorporated vessel does appear to be statistically significant in causing delayed aneurysmal occlusion, but most $(85.7 \%)$ still do occlude with time. Delayed vessel thrombosis is distinctly uncommon and may be asymptomatic. Some aneurysms continue to represent a challenge, and life-long DAT may be required.

\section{ACKNOWLEDGMENTS}

We thank Dr Ferry Dharsono (Neurological Intervention and Imaging Service of Western Australia, Perth, Australia) for assistance in data analysis, and Drs Jonathon Downer (Neurological Intervention and Imaging Service of Western Australia, Perth, Australia), Grace Aw (Prince of Wales Hospital, Sydney, Australia), and Sean Wallace (Gold Coast University Hospital, Gold Coast, Australia) for assistance in data entry.

Disclosures: Albert H.Y. Chiu-UNRELATED: Travel/Accommodations/Meeting Expenses Unrelated to Activities Listed: ev3/Covidien, Comments: ev3 supports an official interventional neuroradiologist-led morbidity and mortality meeting (Neuroexchange) for Australia and New Zealand practitioners, in which all devices from all companies are discussed freely. This meeting runs every year and is open to all practicing Australian and New Zealand interventional neuroradiologists and fellows. ev3 supplies economy return tickets and accommodations. No money is paid directly to me or my institution. I have attended this meeting since 2012. Andrew K. Cheung-UNRELATED: Travel/Accommodations/Meeting Expenses Unrelated to Activities Listed: Neuroexchange, Comments: This is the official interventional neuroradiologist-led morbidity and mortality meeting for Australasia run by members of Australia and New Zealand Society of Neuroradiology, which is supported by ev3. ev3 supplies economy return tickets and accommodations but has no control over 
agenda or material reviewed. All devices available are discussed with no ev3 bias. Jason D. Wenderoth-UNRELATED: Consultancy: ev3, Covidien, Comments: proctoring on Pipeline cases and consultancy fee for attendance and input at faculty meetings during development of the Pipeline Flex device; Travel/Accommodations/Meeting Expenses Unrelated to Activities Listed: ev3/Covidien, Comments: There is an annual Australia/New Zealand morbidity and mortality meeting sponsored by ev3/Covidien (Neuroexchange). All Australia and New Zealand interventional neuroradiologists are offered travel and accommodation expenses to attend this meeting. Most or all attend in this capacity on an annual basis, including myself. Henry Rice-RELATED: Support for Travel to Meetings for the Study or Other Purposes: Covidien, ${ }^{*}$ Comments: travel support to interventional neuroradiologist meetings; UNRELATED: Travel/Accommodations/Meeting Expenses Unrelated to Activities Listed: Cordis, ${ }^{*}$ Stryker, ${ }^{*}$ Covidien. ${ }^{*}$ Constantine C. Phatouros—UNRELATED: Travel/Accommodations/Meeting Expenses Unrelated to Activities Listed: Covidien, Comments: Neuroexchange Meeting: This is the official interventional neuroradiologist-led morbidity and mortality meeting for Australia and New Zealand, which is chaired by members of the Australia and New Zealand Society of Neuroradiology and financially supported by Covidien. Covidien provides return economy (coach) air travel and accommodations but does not have any direct control over the meeting agenda or material presented. Devices across the entire spectrum of interventional neuroradiology are discussed and are not limited to those of Covidien. Tejinder P. Singh-OTHER RELATIONSHIPS: ev3 sponsors a yearly Neuroexchange Meeting in Australia, where the company provides travel to and accommodations at the event. They facilitate the meeting, but no money is provided either to me or the institution. The meeting is a generic interventional neuroradiologist meeting not specific to ev 3 or its products and is a forum to showcase and discuss interventional neuroradiologist techniques and complications. I have attended these meetings. Timothy J. Phillips-UNRELATED: Travel/Accommodations/Meeting Expenses Unrelated to Activities Listed: Covidien, Comments: Neuroexchange Meeting: This is the official interventional neuroradiologist-led morbidity and mortality meeting for Australia and New Zealand, which is chaired by members of the Australia and New Zealand Society of Neuroradiology and financially supported by Covidien. Covidien provides return economy (coach) air travel and accommodations but does not have any direct control over the meeting agenda or material presented. Devices across the entire spectrum of interventional neuroradiology are discussed and are not limited to those of Covidien. William McAuliffe-UNRELATED: Travel/Accommodations/Meeting Expenses Unrelated to Activities Listed: Neuroexchange Morbidity and Mortality National Australasian Interventional Neuroradiologist Meeting, Comments: This is the official interventional neuroradiologist-led morbidity and mortality meeting for Australasia run by members of Australia and New Zealand Society of Neuroradiology, which is supported by ev3. It is a serious 2-day meeting held to review complications and so forth. ev3 supplies economy return tickets and accommodations but has no control over agenda or material reviewed. All devices available are discussed with no ev3 bent. *Money paid to the institution.

\section{REFERENCES}

1. Lylyk P, Miranda C, Ceratto R, et al. Curative endovascular reconstruction of cerebral aneurysms with the Pipeline embolization device: the Buenos Aires experience. Neurosurgery 2009;64:632-42; discussion 642-43; quiz N636

2. Szikora I, Berentei Z, Kulcsar Z, et al. Treatment of intracranial aneurysms by functional reconstruction of the parent artery: the Budapest experience with the Pipeline embolization device. AJNR Am J Neuroradiol 2010;31:1139-47

3. Nelson PK, Lylyk P, Szikora I, et al. The Pipeline embolization device for the intracranial treatment of aneurysms trial. AJNR Am J Neuroradiol 2011;32:34-40

4. McAuliffe $\mathrm{W}$, Wycoco V, Rice $\mathrm{H}$, et al. Immediate and midterm results following treatment of unruptured intracranial aneurysms with the Pipeline embolization device. AJNR Am J Neuroradiol 2012;33:164-70

5. Saatci I, Yavuz K, Ozer C, et al. Treatment of intracranial aneurysms using the Pipeline flow-diverter embolization device: a singlecenter experience with long-term follow-up results. AJNR Am J Neuroradiol 2012;33:1436-46

6. Fischer S, Vajda Z, Aguilar Perez M, et al. Pipeline embolization device (PED) for neurovascular reconstruction: initial experience in the treatment of 101 intracranial aneurysms and dissections. Neuroradiology 2012;54:369-82

7. Phillips TJ, Wenderoth JD, Phatouros CC, et al. Safety of the Pipeline embolization device in treatment of posterior circulation aneurysms. AJNR Am J Neuroradiol 2012;33:1225-31

8. Velat GJ, Fargen KM, Lawson MF, et al. Delayed intraparenchymal hemorrhage following Pipeline embolization device treatment for a giant recanalized ophthalmic aneurysm. J Neurointerv Surg 2012;4:e24

9. Cruz JP, Chow M, O'Kelly C, et al. Delayed ipsilateral parenchymal hemorrhage following flow diversion for the treatment of anterior circulation aneurysms. AJNR Am J Neuroradiol 2012;33:603-08

10. Chiu AH, Wenderoth J. Cerebral hyperperfusion after flow diversion of large intracranial aneurysms. J Neurointerv Surg 2013;5:e48

11. Hu YC, Deshmukh VR, Albuquerque FC, et al. Histopathological assessment of fatal ipsilateral intraparenchymal hemorrhages after the treatment of supraclinoid aneurysms with the Pipeline embolization device. J Neurosurg 2014;120:365-74

12. Delgado Almandoz JE, Crandall BM, Scholz JM, et al. Pre-procedure $\mathrm{P} 2 \mathrm{Y} 12$ reaction units value predicts perioperative thromboembolic and hemorrhagic complications in patients with cerebral aneurysms treated with the Pipeline embolization device. J Neurointerv Surg 2013;5(suppl 3):iii3-10

13. Kulcsár Z, Houdart E, Bonafe A, et al. Intra-aneurysmal thrombosis as a possible cause of delayed aneurysm rupture after flow-diversion treatment. AJNR Am J Neuroradiol 2011;32:20-25

14. Shobayashi Y, Tateshima S, Kakizaki R, et al. Intra-aneurysmal hemodynamic alterations by a self-expandable intracranial stent and flow diversion stent: high intra-aneurysmal pressure remains regardless of flow velocity reduction. J Neurointerv Surg 2013;5(suppl 3):iii38-42

15. Puffer RC, Kallmes DF, Cloft HJ, et al. Patency of the ophthalmic artery after flow diversion treatment of paraclinoid aneurysms. J Neurosurg 2012;116:892-96

16. Heller RS, Dandamudi V, Lanfranchi M, et al. Effect of antiplatelet therapy on thromboembolism after flow diversion with the Pipeline embolization device. J Neurosurg 2013;119:1603-10

17. Yavuz K, Geyik S, Saatci I, et al. Endovascular treatment of middle cerebral artery aneurysms with flow modification with the use of the Pipeline embolization device. AJNR Am J Neuroradiol 2014;35:529-35

18. Brinjikji W, Cloft HJ, Fiorella D, et al. Estimating the proportion of intracranial aneurysms likely to be amenable to treatment with the Pipeline embolization device. J Neurointerv Surg 2013;5:45-48

19. O'Kelly CJ, Spears J, Chow M, et al. Canadian experience with the Pipeline embolization device for repair of unruptured intracranial aneurysms. AJNR Am J Neuroradiol 2013;34:381-87

20. Klisch J, Turk A, Turner R, et al. Very late thrombosis of flow-diverting constructs after the treatment of large fusiform posterior circulation aneurysms. AJNR Am J Neuroradiol 2011;32:627-32

21. Fiorella D, Hsu D, Woo HH, et al. Very late thrombosis of a Pipeline embolization device construct: case report. Neurosurgery 2010;67(3 suppl operative):onsE313-14; discussion onsE314.

22. Chalouhi N, Starke RM, Yang S, et al. Extending the indications of flow diversion to small, unruptured, saccular aneurysms of the anterior circulation. Stroke 2014;45:54-58

23. Becske T, Kallmes DF, Saatci I, et al. Pipeline for uncoilable or failed aneurysms: results from a multicenter clinical trial. Radiology 2013;267:858-68

24. Lubicz B, Collignon L, Raphaeli G, et al. Pipeline flow-diverter stent for endovascular treatment of intracranial aneurysms: preliminary experience in 20 patients with 27 aneurysms. World Neurosurg 2011;76:114-19

25. Yu SC, Kwok CK, Cheng PW, et al. Intracranial aneurysms: midterm outcome of Pipeline embolization device-a prospective study in 143 patients with 178 aneurysms. Radiology 2012;265:893-901

26. Deutschmann HA, Wehrschuetz M, Augustin M, et al. Long-term follow-up after treatment of intracranial aneurysms with the Pipeline embolization device: results from a single center. AJNR Am J Neuroradiol 2012;33:481-86 